\title{
Air in the biliary duct as an indicator of Type V Mirizzi syndrome: a case report
}

\author{
Jun-Wei Zhang ${ }^{1}$, Feng Tian' ${ }^{2}$ Bing-Qi Li ${ }^{2}$, Yi-Zhi Wang' ${ }^{2}$ Jun-Chao Guo ${ }^{2}$ \\ ${ }^{1}$ Department of Liver Surgery, ${ }^{2}$ Department of General Surgery, Peking Union Medical College (PUMC) Hospital, Chinese Academy of Medical \\ Sciences and Peking Union Medical College (CAMS \& PUMC), Beijing 100730, China \\ Correspondence to: Jun-chao Guo, Professor, Department of General Surgery, Peking Union Medical College Hospital, 1 Shuai Fu Yuan, Wangfujing, \\ Beijing 100730, China. Email: gjcpumch@163.com.
}

\begin{abstract}
Mirizzi syndrome, known as extrinsic bile compression syndrome (EBCS), is difficult to diagnose without surgery. To the best of our knowledge, our case shows that air in the biliary duct may indicate Type V Mirizzi syndrome. A 48-year-old Chinese male, complaining of anorexia with weight loss and jaundice, showed decreased bilirubin for two months after being diagnosed with gallbladder stones. Upon reexamination of the CT, evidence of air in the biliary duct was discovered. Type V EBCS was finally diagnosed during surgery. The patient underwent cholecystectomy, cholecystocolic fistula excision, and Roux-en-Y choledochojejunostomy. The postoperative course was uneventful. Mirizzi's syndrome is a condition which is difficult to diagnose and treat. Air in the biliary duct can be a sign of Type V Mirizzi syndrome, which aids in diagnosis of Type V EBCS before surgery. Cholecystectomy, fistula excision and biliary-enteric anastomosis with Roux-en-Y loop appear to be the most appropriate surgical interventions for the condition.
\end{abstract}

Keywords: Air; biliary duct; Mirizzi syndrome; case report

Submitted Nov 06, 2019. Accepted for publication Dec 09, 2019.

doi: $10.21037 /$ tcr.2019.12.25

View this article at: http://dx.doi.org/10.21037/tcr.2019.12.25

\section{Introduction}

Mirizzi's syndrome, known as extrinsic bile compression syndrome (EBCS), is a rare complication of gallstones, which was first described by Pablo Luis Mirizzi in 1948. Type V EBCS, in which the condition is complicated by cholecystoenteric fistula, exhibits both high mortality and morbidity $(1,2)$.

Cases diagnosed with certainty before surgical exploration range from $8 \%$ to $63.4 \%$ (3). Earlier diagnosis of Type V MS can help the surgeon to plan more adequately before surgery. Our case demonstrates that air in the biliary duct is a sign of Type V EBCS. In conclusion, this case is instructive in diagnosis of the condition prior to surgery.

We present the following case in accordance with the CARE Guidelines. please refer to the article "Jun-Wei Zhang, Feng Tian, Bing-Qi Li, Yi-Zhi Wang, Jun-Chao Guo. Air in the biliary duct as an indicator of Type V Mirizzi syndrome: a case report".

\section{Case presentation}

A 48-year-old Chinese male presented himself to our clinic, complaining of anorexia with weight loss and jaundice. He had no medical history of disease, and no inherited diseases. Blood tests done in the outpatient clinic on 201809-18 showed alanine aminotransferase (ALT) $111 \mathrm{U} / \mathrm{L}$ (normal 9-50 U/L), galactosyl glucosyltransferase (GGT) 787 U/L (normal 10-60 U/L), alkaline phosphatase (ALP) $547 \mathrm{U} / \mathrm{L}$ (normal 45-125 U/L), total bilirubin (TB) $29.9 \mu \mathrm{mol} / \mathrm{L}$ (normal 5.1-22.2 $\mu \mathrm{mol} / \mathrm{L}$ ), direct bilirubin (DB) levels $21.7 \mu \mathrm{mol} / \mathrm{L}$ (normal less than $6.8 \mu \mathrm{mol} / \mathrm{dL}$ ) (Table 1). Ultrasound of the abdomen showed intrahepatic bile duct dilatation and a large gallstone about $4.4 \times 1.8 \mathrm{~cm}^{2}$ in size located in the neck of gallbladder. MRI and MRCP indicated intrahepatic duct dilatation and low signal intensity in the gallbladder (Figure 1).

The patient was admitted to the hospital and blood tests were performed on 2018-11-08. They showed his ALT 
Table 1 The blood test of the patient

\begin{tabular}{lcc}
\hline & $2018-09-18$ & $2018-11-08$ \\
\hline ALT $(9-50 \mathrm{U} / \mathrm{L})$ & 111 & 65 \\
GGT $(10-60 \mathrm{U} / \mathrm{L})$ & 787 & 773 \\
ALP $(45-125 \mathrm{U} / \mathrm{L})$ & 547 & 547 \\
TB $(5.1-22.2 \mu \mathrm{mol} / \mathrm{L})$ & 29.9 & 14.7 \\
DB $(<6.8 \mu \mathrm{mol} / \mathrm{dL})$ & 21.7 & 10.2 \\
\hline
\end{tabular}

ALT, alanine aminotransferase; GGT, galactosyl glucosyltransferase; ALP, alkaline phosphatase; TB, total bilirubin; DB, direct bilirubin.

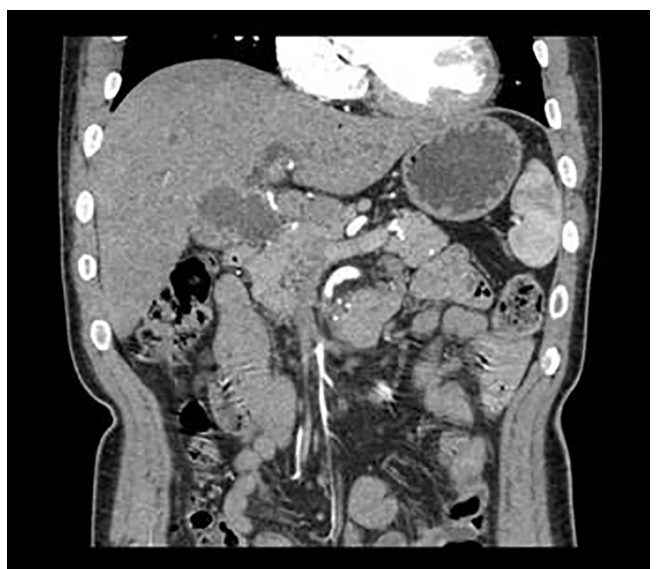

Figure 1 MRI: multiple filling defects in the gallbladder, the size of the area is about $3.0 \mathrm{~cm} \times 2.5 \mathrm{~cm}$. The common bile duct also exhibits filling defects and intrahepatic bile duct dilatation.

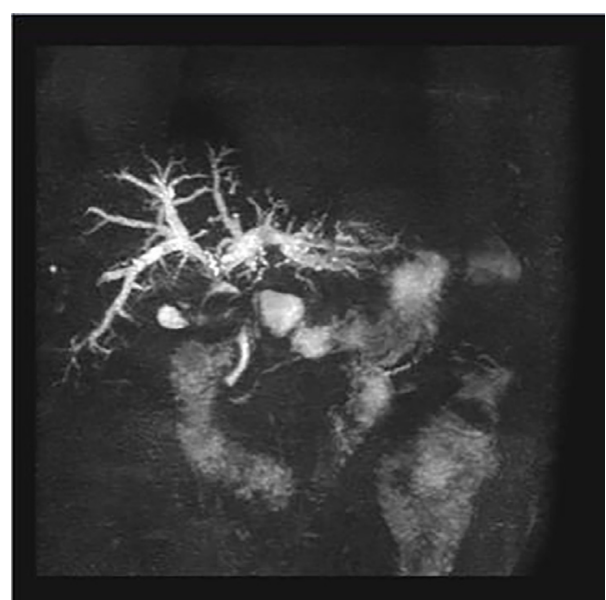

Figure 2 CT: the gallbladder area has a round shape with a slightly lower density. The gallbladder is poorly filled, the wall is thickened, and the normal structure of the cystic duct is unclear.

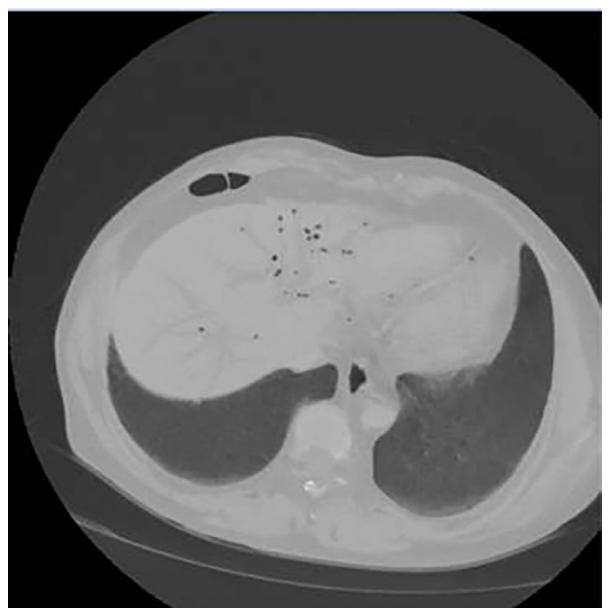

Figure 3 Spiral CT with evidence of pneumobilia.

$65 \mathrm{U} / \mathrm{L}$ (normal 9-50 U/L), GGT $773 \mathrm{U} / \mathrm{L}$ (normal 10-60 U/L), ALP 547 U/L (normal 45-125 U/L), TB levels $14.7 \mu \mathrm{mol} / \mathrm{L}$ (normal 5.1-22.2 $\mu \mathrm{mol} / \mathrm{L}$ ), DB levels $10.2 \mu \mathrm{mol} / \mathrm{L}$ (normal less than $6.8 \mu \mathrm{mol} / \mathrm{dL}$ ) (Table 1). Computed tomography of the abdomen showed a large calculus at Hartmann's pouch had obstructed the common bile duct (CBD), as well as the presence of air in the biliary duct. (Figures 2,3). We did not perform endoscopic retrograde cholangiopancreatography before surgery, because the patient no longer exhibited frank jaundice.

As for the diagnosis, gallstones were definitely the first consideration. And the patient had increased DB, which led us to the diagnosis of bile duct stones. However, cholecystolithiasis with bile duct stone could not explain air in the bile duct or the decreased TB (from 29.9 to $14.7 \mu \mathrm{mol} / \mathrm{L}$ ) before surgery, making presurgical diagnosis difficult. Finally, the patient agreed to the surgery, and 


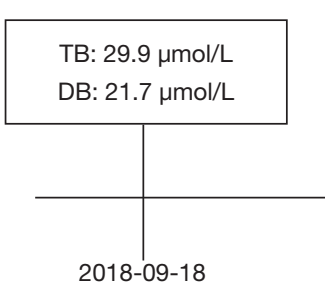

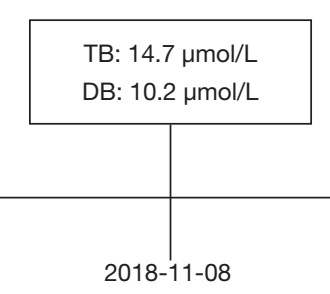
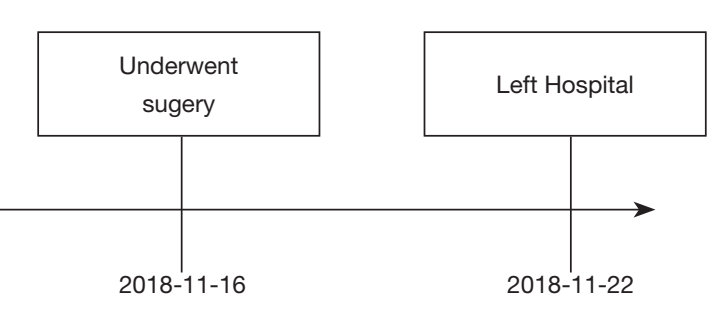

Figure 4 Timeline of the patient's condition.

consented to changes in the operative procedures as necessary.

Definitive diagnosis of two internal fistulas was made intraoperatively. First, we planned to do a laparoscopic cholecystectomy. However, during laparoscopic exploration, adhesions were found between the gallbladder and the duodenum. We then opted for open cholecystectomy. We incised rectus abdominis in the right upper quadrant, and found the gallbladder neck, CBD and hepatic duct tightly adhered and difficult to separate. The gallbladder was filled with calculi and a small amount of bile. The largest stone was about $4 \mathrm{~cm}$ in diameter. The base of the gallbladder had formed a fistula with the duodenum, and the gallbladder neck, packed with calculi, had penetrated the common hepatic duct, which is consistent with Mirizzi syndrome. The final intervention was cholecystectomy, cholecystocolic fistula excision and side-to-side Roux-en-Y choledochojejunostomy. The postoperative pathology was gallbladder adenomyomatosis and the postoperative course was uneventful. The patient was discharged a week after the operation. The patient's historical and current information can be seen in the timeline image (Figure 4).

\section{Discussion}

Mirizzi syndrome, also known as EBCS, is a rare complication in which the $\mathrm{CBD}$ is obstructed by compression caused by the impaction of one or more gallstones in the cystic duct. In 2007, Beltran et al. added a Type V EBCS to the original four classifications, which validated the relationship of Mirizzi Syndrome to cholecystoenteric fistula (1).

Because Type V EBCS is a novel classification, there are only few case reports detailing it $(4,5)$. To the best of our knowledge, ours shows that air in the biliary duct may be a sign of Type V EBCS. The fistula present between the gallbladder and the duodenum allows air to infiltrate the bile duct and bile to drain into the duodenum, which explains the patient's decreased bilirubin levels and why some patients do not exhibit jaundice.

A search of the PubMed, Embase and Web of Science databases for the terms "aerobilia" and "Mirrizi syndrome" revealed two cases of Type V EBCS with aerobilia $(5,6)$ caused by fistula or infection, the former corresponding to Type V EBCS $(7,8)$.

Mirizzi syndrome is a dangerous anatomical transformation, representing a particular challenge for the biliary surgeon, and bears significant potential for morbidity and biliary injury. Preoperative recognition of this condition is important for avoidance of inadvertent ligation or severance of the bile duct. Surgical treatment should be planned after a careful assessment of the local situation and anatomy. Our case is instructive for surgeons in diagnosis of Type V Mirizzi syndrome prior to surgery, providing an avenue for more effective planning. However, our case has limitations, because air in the bile duct can be seen in other conditions, such as the uncomplicated biliary fistula, and Type $\mathrm{V}$ Mirizzi needs to be diagnosed by enhanced CT, MRCP and ultrasound combined intraoperative exploration.

\section{Conclusions}

Mirizzi syndrome is difficult to diagnose and treat. Air in the biliary duct as an indicator of this condition can assist in presurgical diagnosis. Cholecystectomy, fistula excision, and biliary-enteric anastomosis with Roux-en-Y loop appear to be the most appropriate surgical interventions for Type V.

\section{Acknowledgments}

Funding: None.

\section{Footnote}

Conflicts of Interest: All authors have completed the ICMJE uniform disclosure form (available at http://dx.doi. org/10.21037/tcr.2019.12.25). The authors have no conflicts of interest to declare. 
Ethical Statement: The authors are accountable for all aspects of the work in ensuring that questions related to the accuracy or integrity of any part of the work are appropriately investigated and resolved. All procedures performed in studies involving human participants were in accordance with the Declaration of Helsinki (as revised in 2013). Written consent was obtained from the patient for publication of this case report. The patient gave consent for his clinical details as well as any identifying images to be published in this study.

Open Access Statement: This is an Open Access article distributed in accordance with the Creative Commons Attribution-NonCommercial-NoDerivs 4.0 International License (CC BY-NC-ND 4.0), which permits the noncommercial replication and distribution of the article with the strict proviso that no changes or edits are made and the original work is properly cited (including links to both the formal publication through the relevant DOI and the license). See: https://creativecommons.org/licenses/by-nc-nd/4.0/.

\section{References}

1. Beltran MA, Csendes A, Cruces KS. The relationship of Mirizzi syndrome and cholecystoenteric fistula:

Cite this article as: Zhang JW, Tian F, Li BQ, Wang YZ, Guo JC. Air in the biliary duct as an indicator of Type V Mirizzi syndrome: a case report. Transl Cancer Res 2020;9(2):12841287. doi: $10.21037 /$ tcr.2019.12.25 validation of a modified classification. World J Surg 2008;32:2237-43.

2. Wichmann C, Wildi S, Clavien PA. The relationship of Mirizzi syndrome and cholecystoenteric fistula: validation of a modified classification. World J Surg 2008;32:2244-5.

3. Clemente G, Tringali A, De Rose AM, et al. Mirizzi Syndrome: Diagnosis and Management of a Challenging Biliary Disease. Can J Gastroenterol Hepatol 2018;2018:6962090.

4. Faridi MS, Pandey A. Mirizzi Syndrome Type II with Cholecystoduodenal Fistula: An Infrequent Combination. Malays J Med Sci 2014;21:69-71.

5. Chatzoulis G, Kaltsas A, Danilidis L, et al. Mirizzi syndrome type IV associated with cholecystocolic fistula: a very rare condition--report of a case. BMC Surg 2007;7:6.

6. Beltran MA, Csendes A. Mirizzi syndrome and gallstone ileus: an unusual presentation of gallstone disease. J Gastrointest Surg 2005;9:686-9.

7. Vialle R, L'Helgouarc'h J L, Burdy G, et al. [Aerobilia: a rare consequence of anaerobic acute cholecystitis: a case report]. Gastroenterol Clin Biol 2002;26:289-91.

8. Schiemann U, Dayyani V, Muller-Lisse UG, et al. Aerobilia as an initial sign of a cholecystoduodenal fistula-a case report. MMW Fortschr Med 2004;146:39-40. 